\title{
Reformas de
}

\author{
Ana Sojo \\ Oficial de Asuntos Sociales \\ asojo@eclac.cl \\ CEPAL
}

\section{gestión en salud en América Latina}

Tras un análisis conceptual del término cuasimercados, el artículo aborda cuatro experiencias de reforma de la gestión en salud en tres escenarios con diversa vigencia de los principios de solidaridad y universalidad del modelo de salud. En Chile los cambios se insertan en la reforma previa, la más radical de la región en cuanto a socavar la solidaridad y universalidad del modelo de salud. Se concluye que sería beneficioso consolidar los aspectos netamente de gestión para avanzar hacia el uso de precios administrados, tener información pertinente sobre la calidad y costos de las atenciones y contribuir a implantar criterios de eficiencia y eficacia en las prestaciones clínicas. En Colombia y Argentina, pese a grandes diferencias entre ambos casos, los cambios están insertos en un escenario de reforma que propicia la competencia y propugna los principios de solidaridad y universalidad; por haberse centrado principalmente en modificaciones al modelo de financiamiento, dieron de partida un lugar subalterno a la gestión. En el caso colombiano el artículo destaca las excesivas complejidades del financiamiento hospitalario que, unidas a insuficiencias regulatorias, coartan los cambios en la gestión. En el caso argentino, que exhibe hospitales sobredimensionados, describe la amplia gama de reformas de la gestión hospitalaria derivada de la descentralización previa, el grado de autonomía respecto de la disciplina fiscal y las diversas concepciones de su inserción en los sistemas de referencia. En el caso de Costa Rica, con un escenario de salud eminentemente público y basado en principios de solidaridad y universalidad, el artículo indaga en la constitución de mercados internos de salud mediante la introducción en la Caja Costarricense Seguros de Salud de un nuevo modelo organizativo y de financiamiento asociado al desempeño; señala que los compromisos de gestión involucrados tienen interesantes aspectos de organización e información y de conformación de un sistema de salud, pero también una excesiva complejidad y altos costos de transacción, y analiza las dificultades para implantar una efectiva descentralización de los prestadores y establecer incentivos al desempeño. 
I

\section{Introducción}

Los cuasi mercados en salud promueven una competencia de proveedores y/o de aseguradores, pero difieren de los mercados convencionales en algunos aspectos. En cuanto a la demanda, el poder comprador se expresa mediante un presupuesto que se pacta con el ente público comprador. Los consumidores están representados por agentes, es decir, por una entidad compradora cuyo carácter está determinado por la organización del cuasi mercado y por las reglas del juego del aseguramiento. Los precios se negocian o administran en un marco presupuestario. En cuanto a la oferta, ésta puede comprender una variedad de formas de propiedad - estatal, municipal, fideicomisos (trusts), consorcios y organizaciones sin fines de lucro- que pueden estar sometidas a diversas reglas de financiamiento (Bartlett y Le Grand, 1993, pp. 23 y 24).

Los elementos de competencia pueden introducirse en diferentes planos: sea al modificar la combinación público-privada, ampliando la participación privada; o al cambiar el estatuto de las instituciones públicas prestadoras, atribuyéndoles mayor autonomía en el uso de los recursos en un ambiente competitivo regido por el marco regulatorio de un contrato, o al posibilitar que éstas se acojan al derecho privado. Diversos mecanismos pueden promover la competencia dentro de los prestadores, tales como la libre elección en el sistema de referencia o de los profesionales, o la competencia por presupuestos entre hospitales.

Los cuasi mercados obedecen a dos racionalidades. ${ }^{1}$ En relación con los prestadores públicos, buscan introducir competencia en el ámbito público mediante la separación de funciones, para mejorar su eficiencia

\footnotetext{
$\square$ Agradecemos a Jairo Restrepo y al equipo de investigación del Centro de Investigaciones Económicas de la Universidad de Antioquia la discusión que realizaron de una versión previa de este artículo y sus comentarios sobre el concepto de salud y la reforma colombiana, y a Oscar Altimir sus observaciones en torno a esta versión.

${ }^{1}$ En un diálogo, Rebeca Grynspan distinguió dos racionalidades singulares, que en la argumentación sobre el tema generalmente se han planteado de modo implícito.
}

y calidad. Respecto a una combinación público-privada (al considerar la salud como bien público porque sus externalidades positivas exceden los beneficios individuales, o como bien meritorio que actualiza un derecho social), se trata de hacer efectiva la demanda por encima de los precios del prestador, las condiciones de salud de las personas y su capacidad de pago, aplicando reglas del juego para el aseguramiento, el financiamiento y la prestación que establecen condiciones de solidaridad mediante subsidios cruzados entre estratos de ingreso, grupos de riesgo o de edad, o bien mediante subsidios a grupos específicos. En ambos casos, el financiamiento se vincula con productividad, cobertura, rendimiento y cumplimiento de metas.

En América Latina y el Caribe se están realizando reformas de gestión que representan movimientos hacia la constitución de cuasi mercados. Estas reformas han surgido en modelos de salud disímiles en cuanto a sus principios articuladores, las responsabilidades del sector público y del privado, la cobertura de prestaciones y de la población, los modelos de financiamiento y de aseguramiento, y la regulación. En muchos casos, la base jurídica de los mecanismos introducidos es endeble, los precios cumplen una función estrictamente teórica, y su consolidación plantea modificaciones de gran complejidad política en el ámbito de los recursos humanos. Con todo, la perspectiva de que se desarrollen cuasi mercados es una alternativa interesante para alcanzar los objetivos de mayor eficiencia, capacidad de respuesta ${ }^{2}$ y posibilidad de elección, sin consecuencias adversas en términos de inequidad. El presente artículo analiza las reformas de gestión implantadas en Chile, Colombia, Argentina y Costa Rica, considerando los avances que representaron y los obstáculos que emergieron en su funcionamiento.

\footnotetext{
2 Serían pertinentes conceptos como "accountability" o "responsiveness", que no tienen una adecuada traducción al castellano.
} 


\section{II}

\section{Chile: ajustes de gestión, cuando la solidaridad y la universalidad han sido socavadas}

Lo radical de la reforma chilena del decenio de 1980, posibilitada por el contexto autoritario, no tiene parangón. El contrapunto por excelencia es la suerte de la experiencia inglesa con los gobiernos conservadores de Thatcher y Major, dado que los conservadores impugnaban radicalmente la forma de financiamiento, el ámbito de las prestaciones y la combinación públicoprivada del sistema nacional de salud británico (NHS). Tras variadas circunstancias políticas que impidieron cambios radicales, paradójicamente el NHS se modificó mediante una profundización de la separación de funciones que promueve la competencia. ${ }^{3}$

El aseguramiento obligatorio es propio de los llamados seguros sociales, públicos o nacionales, que buscan una diferenciación de riesgos estable y pueden tener propósitos redistributivos y solidarios, dentro de variadas combinaciones público-privadas. El sistema de salud chileno, por lo tanto, es sui generis en el plano internacional. En su lógica dual, la cotización obligatoria, a cargo exclusivo del trabajador, permite a éste afiliarse al sistema público de salud a través del Fondo Nacional de Salud (FONASA), cuya racionalidad de reparto favorece la solidaridad, o bien a las instituciones de salud previsional (ISAPRES) que, sin embargo, funcionan con una lógica de seguro privado asociada al riesgo individual.

El FONASA da acceso a prestaciones públicas en la llamada modalidad institucional o a prestaciones privadas mediante la modalidad de libre elección, sujeta a diversos copagos, y se nutre también de otros aportes con cargo al presupuesto público. Las ISAPRES, al contrario de la lógica propia del aseguramiento obligatorio, aseguran mediante planes individuales que se renuevan cada año y plasman así una selección de riesgo, al ajustarse su precio y su cobertura a la edad, ries-

\footnotetext{
${ }^{3}$ Ya existía la contratación de la atención ambulatoria con los médicos generales (general practitioners); después se introdujo la autonomía de los hospitales para funcionar bajo contrato del sistema público de salud, lo cual dio paso a la agrupación de prestadores en trusts. Sobre la reforma del sistema inglés, véase Ferlie y otros (1996), Walsh (1995), Bach (1999) y Winchester y Bach (1999). Véase también un tratamiento detallado del proceso político en Porter (1999), pp. 236-259.
}

go en salud y sexo del asegurado. Las ISAPRES cubren a cerca del $30 \%$ de la población, y sus precios han experimentado un alza que supera con creces las de otros sectores de la economía. ${ }^{4} \mathrm{El}$ sector público, desprovisto de barreras de entrada, cubre a la población de menores ingresos y a la de mayores riesgos, y cumple una función de reaseguro global del sistema.

Hasta ahora, las medidas que apuntan a mejorar la gestión del sector público de salud en Chile constituyen un ajuste y pretenden elevar la eficiencia y eficacia del subsistema público, sin modificar el diseño dual de la combinación público-privada introducida en el decenio de 1980.

\section{Dimensiones organizativas y rasgos de los contratos $^{5}$}

Los compromisos de gestión entre el nivel central y los servicios de salud se introdujeron en 1995, para asignar y transferir recursos a las entidades prestadoras según un acuerdo anual de servicios por brindar, que establecía indicadores de desempeño. Se alentaba a estas entidades a que, a su vez, establecieran contratos con los hospitales públicos y municipalidades con los cuales se relacionan. ${ }^{6}$

Gradualmente, los compromisos han contribuido a ordenar las relaciones entre los servicios de salud y el nivel central, tradicionalmente sujetas a acuerdos bilaterales formales e informales entre instancias específicas que acarreaban descoordinación, duplicaciones y contraposiciones, y llevaban a dedicar cuantiosos recursos a cabildeos. Al mantener el Ministerio de

\footnotetext{
${ }^{4}$ Algunas cifras ilustran esta afirmación: mientras que en 1990 la cotización adicional media de los cotizantes de las ISAPRES era del 0,7\% de la remuneración media del sistema, en 1996 había aumentado al $1.3 \%$. Entre ambos años el valor de las consultas médicas privadas subió 55\% en términos reales (Baeza y otros, 1998, pp. 18 y 19).

5 Véase detalles sobre los compromisos de gestión chilenos y su contexto en Sojo (1996, 1998 y 1999a).

${ }^{6}$ Existen compromisos de gestión entre otras instancias en el sector salud. Aquellos con los servicios de salud representan el grueso del gasto en salud, de modo que en adelante nos referiremos exclusivamente a estos contratos.
} 
Salud funciones prestadoras, característica que se ha señalado como un obstáculo importante en la reestructuración del sector salud, ${ }^{7}$ inicialmente los compromisos también se estructuraron y evaluaron en forma atomizada, lo que se ha ido superando. ${ }^{8}$

La función de compra, sin embargo, sigue siendo una función "teórica" dentro del sistema de salud. Con excepción de casos particulares y de limitado impacto en el presupuesto global, como los programas de prestaciones complejas o de oportunidad de la atención, los precios son fundamentalmente un sistema de referencia (Lenz, 1998, pp. 193 y 194) y no están determinados por los términos del contrato.

Aunque los indicadores de los contratos cubren los tres niveles de atención de salud, hacen hincapié en la atención primaria y preventiva. Las metas se expresan fundamentalmente en índices de actividad y de cobertura. Se han mejorado los indicadores sanitarios, que al inicio eran muy débiles, y también la vinculación con las metas ministeriales y gubernamentales. El número de indicadores se ha ido multiplicando, lo que ha cimentado su uso ritualista, dificultado una adecuada evaluación y representado altos costos de transacción.

Se ha buscado optimizar la red de prestaciones, con el apoyo de los compromisos de gestión. El FONASA se ha constituido en un intermediario entre los servicios y, para articular la red en las regiones, se ha reestructurado en cinco zonas que abarcan varios servicios. Se han creado "mesas" regionales, que hacen el seguimiento de los compromisos, ${ }^{9}$ y los contratos contemplan actividades para fortalecer el Programa de Oportunidad de la Atención, en la atención primaria, y reforzar la articulación de la atención primaria rural.

Pero, paradójicamente, la ejecución —que constituye el núcleo de la gestión- ha quedado al libre albedrío de los servicios de salud y no ha sido integrada plenamente en los compromisos. ${ }^{10}$ Los objetivos organizacionales o la definición de los productos intermedios que han de ser comprados han sido marginales, al igual que la introducción o mejora de sistemas de información, la optimización de procesos que

\footnotetext{
${ }^{7}$ Entrevista con César Oyarzo, ex Director del FonAsA, realizada el 22 de agosto de 1997.

${ }^{8}$ Entrevista del 3 de septiembre de 1997 con Pedro Croco, entonces Director de la Unidad de Gestión del Ministerio de Salud.

${ }^{9}$ Entrevista con Rony Lenz, entonces Director del fonAsa, el 26 de mayo de 1998.

${ }^{10}$ Este derrotero de los compromisos fue expuesto por Rony Lenz en la misma entrevista. Sus referencias a la debilidad que tienen los compromisos de gestión se dieron como respuesta a nuestro planteamiento crítico sobre el punto en la entrevista, con el cual coincidió.
}

no venían funcionando adecuadamente, o el desarrollo de nuevos procesos que eleven la eficacia y permitan sistematizar la prestación de servicios. No ha habido una mejora importante de los registros como instrumento para fortalecer la capacidad de gestión.

Para incrementar la productividad de los recursos humanos está pendiente modificar las modalidades de contratación y remuneración vigentes. Diferentes rigideces en el manejo de los recursos humanos dificultan innovar en la gestión. Los sectores afectados han impedido beligerantemente la modificación de la ley $\mathrm{N}^{\circ} 15.076$ que rige las modalidades de contratación y remuneración de los profesionales de los servicios de salud. Así, se ha relegado hasta la actualidad un proyecto de ley que en 1995 pretendía flexibilizar y descentralizar significativamente la conformación de las plantas; sumar a la antigüedad de la carrera funcionaria el reconocimiento del desempeño, del mérito y de la eficacia; fomentar la asignación de responsabilidades individuales y entrelazar el reconocimiento del desempeño individual con el institucional, y condicionar a concursos la permanencia en el sistema (Sojo, 1996).

\section{Por una adecuada integración en la reforma}

Los compromisos de gestión podrían cumplir un papel en ámbitos que constituyen obstáculos fundamentales para la reforma. Por ejemplo, en lo que se refiere a la política arancelaria y de costos, la información básica de los hospitales es deficiente; en el programa de patologías complejas, no hay una red nacional de derivación explícita. Si los compromisos de gestión incluyeran innovación de procesos permitirían acopiar información útil sobre la calidad y los costos de la atención o implantar criterios de eficiencia y eficacia en la decisión clínica. De allí que la débil integración de los aspectos de gestión en los contratos limita su impacto, porque coarta interacciones beneficiosas y eficientes con la reforma sectorial.

Por ejemplo, el pago asociado a diagnóstico (PAD) no ha sustituido a la asignación histórica del presupuesto, sino que se ha utilizado en forma paralela y con carácter experimental en programas específicos, como el de prestaciones complejas y el de oportunidad de la atención. Habiéndose introducido con un alto grado de participación en el nivel hospitalario, no fue percibido como una amenaza, pero colapsó cuando la diversidad de condiciones iniciales y las deficiencias de información hicieron inviable su uso masivo. ${ }^{11}$ Consolidar el

\footnotetext{
${ }^{11}$ Esta trayectoria de los PAD nos fue planteada por Rony Lenz, en la entrevista citada.
} 
ámbito de gestión, sea mediante contratos con los servicios de salud o en otras formas, permitiría avanzar en el uso de los PAD, apoyándose por ejemplo en el uso concordado de protocolos clínicos. Tal giro requeriría cautela y sentido de las prioridades.

También es preciso simplificar y reducir fuertemente los indicadores relacionados con el cumplimien- to de tareas especificadas en metas y coberturas. Si se optara por incluir algunos productos intermedios, procesos y sistemas de información, debiera hacerse muy selectivamente y para períodos de tiempo que consoliden su puesta en práctica. Los compromisos de gestión no deben ser confundidos con una planificación por objetivos.

\section{III}

\section{Colombia: la reforma de gestión en un sistema solidario y universal, con competencia}

El impacto redistributivo de la reforma colombiana ha sido importante: en 1993 la cobertura efectiva en salud del quintil superior de la población era 13.6 veces mayor que la del quintil más pobre, brecha que en 1997 se estrechó a 1.86 veces (Colombia, Consejo Nacional de Seguridad Social en Salud, 2000, p. 13). La reforma busca lograr tanto la cobertura universal de la prestación de servicios como la competencia entre aseguradores y prestadores ${ }^{12}$ en un sistema solidario y descentralizado, cuyos beneficios y obligaciones están consolidados en dos regímenes: el contributivo, que se nutre de contribuciones obrero-patronales, y el subsidiado, que se focaliza en los más pobres. El primero está regulado por el plan obligatorio de salud (POS) y el segundo por el plan obligatorio de salud subsidiado (POSs), y ambos deben converger gradualmente.

El Fondo de Solidaridad y Garantía vela por el equilibrio de los recursos y las condiciones de igualdad del régimen contributivo, mediante un pago per cápita, ajustado para evitar la selección de riesgos en las prestaciones. Posee cuatro subcuentas: de compensación, de solidaridad, de promoción y de eventos catastróficos y accidentes de tránsito. Transfiere el 1\% de la cotización de ese régimen al subsidiado, que se suma a los impuestos generales de los cuales éste se nutre. Se pretende ir hacia un financiamiento de las prestaciones mediante el subsidio a la demanda - es

\footnotetext{
12 El aseguramiento de ambos regímenes está a cargo, respectivamente, de las entidades promotoras de salud (EPS) y de las administradoras del régimen subsidiado (ARS); las instituciones prestadoras de salud (IPS) son las prestadoras. Todas ellas pueden tener carácter privado o público.
}

decir, determinado por la demanda efectiva de los asegurados - que reemplace el subsidio a la oferta, como se denomina al financiamiento tradicional de prestadores eminentemente públicos y mediante presupuestos históricos. Las disparidades distributivas y la singular oferta territorial de los prestadores han imposibilitado una sustitución total del uno por el otro, y no se ha llegado a definir una proporción deseable.

En la concepción y trayectoria de la reforma colombiana, sin embargo, se observan serias carencias en cuanto a la integración y complementariedad de la red de servicios y de los niveles de atención. Urge tomar medidas que incrementen la eficiencia microeconómica. La gestión ha tenido un papel secundario, y sus debilidades debieran ser enfrentadas porque conspiran contra el avance general (por ejemplo, inhibiendo la liberación de recursos indispensables para ampliar la cobertura). Esto sucede justamente mientras están en revisión los costos crecientes y los contenidos del aseguramiento del régimen contributivo, para velar por su equilibrio y sustentabilidad financiera, y el aumento de cobertura del régimen subsidiado se ve comprometido por la disminución de los aportes del presupuesto nacional, la evasión del régimen contributivo que afecta los recursos solidarios, y los costos de la transición desde los subsidios a la oferta a los subsidios a la demanda (Colombia, Consejo Nacional de Seguridad Social en Salud, 2000 pp. 13 y 20).

\section{Complejidades y complicaciones del finan- ciamiento hospitalario: repercusiones en el desempeño}

En 1993, la alambicada arquitectura de la reforma incluyó la transformación de los hospitales públicos en 
empresas sociales del Estado (ESE), que son entidades públicas descentralizadas, con personería jurídica, patrimonio propio y autonomía administrativa (cuadro 1). La descentralización vinculó a los hospitales públicos con el poder territorial departamental y municipal (cuadro 2), con lo cual se redujo la influencia del poder nacional, y se generaron tensiones inéditas entre estos tres niveles. De la autonomía territorial se ha afirmado que sufre una frecuente invasión sectorial mediante normas nacionales que definen detalladamente el uso de los recursos territoriales destinados a salud (Vargas y Sarmiento, 1998).

La presión de los hospitales por conservar el financiamiento histórico, unida a los serios déficit de algunos, provocó que la sustitución del subsidio a la oferta por el subsidio a la demanda se congelara por tres años. Sin bases sólidas de información, la transición tolera dobles pagos a los hospitales mediante subsidios a la oferta y a la demanda, duplicaciones del aseguramiento de los dos regímenes e ingresos por facturación de la atención de muchos asegurados para obtener recursos vía oferta (Londoño, Jaramillo y Uribe, 1999). La duplicación de pagos se da también en otros niveles de atención, y además se carece de un adecuado registro del aseguramiento y las prestaciones brindados con recursos específicos a la población desplazada por la violencia. ${ }^{13}$ Luego, es urgente identificar, registrar, relacionar y unificar a escala nacional los datos de los beneficiarios de ambos regímenes o de fondos ad hoc. Este empadronamiento es crucial para evitar filtraciones y duplicaciones y para administrar el sistema de aseguramiento y prestaciones, pero los avances en esta materia son precarios (Colombia,

CUADRO 1

Colombia: Hospitales convertidos en empresas sociales del Estado (ESE), junio de 1998

\begin{tabular}{lccc}
\hline Hospitales & $\mathrm{N}^{\circ}$ total & ESE & Porcentaje \\
\hline Nivel III & 28 & 23 & 82 \\
Nivel II & 125 & 120 & 96 \\
Nivel I & 354 & 194 & 55 \\
Total & 507 & 337 & 66 \\
\hline
\end{tabular}

Fuente: Ministerio de Salud de Colombia, Programa de Mejoramiento de los Servicios de Salud, incluido en Londoño, Jaramillo y Uribe (1999).

${ }^{13}$ Nos lo planteó en una conversación Juan Fernando Alviar, el 22 de mayo de 2001.
Consejo Nacional de Seguridad Social en Salud, 2000, pp. 34 y 35$)$.

El presupuesto de los tres niveles de hospitales públicos se ha incrementado notablemente: entre 1993 y 1997, el del nivel I se multiplicó 2.6 veces; del nivel II, 1.9 veces y del nivel III, 1.5 veces. Su planta médica se duplicó en los diez últimos años, y la escala salarial de los funcionarios públicos del sector se triplicó, alza real mayor que la del promedio de los empleados públicos. El financiamiento hospitalario es muy complejo, ya que sus diversas fuentes se rigen por singulares mecanismos de acceso, lógicas, criterios de asignación, regímenes presupuestarios y flujo de recursos; para extremar la complejidad, también varían las transferencias: por ejemplo, el situado fiscal ${ }^{14}$ destinado a un hospital o centro de salud puede, en primer término, transferirse directamente al municipio, al fondo seccional de salud, o al fondo local de salud (Jaramillo, 2000, pp. 45-46 y 108).

Los recursos otorgados según presupuestos históricos provienen de los niveles nacional y territorial, y el situado fiscal continúa siendo la principal fuente de financiamiento hospitalario. Con esos recursos, los hospitales y la red asistencial pública deben atender a la población vinculada, es decir, la carente de aseguramiento y sin capacidad de pago. Se han eliminado los "auxilios", es decir, aquellos contratos con el Estado para atender a los pobres que ocultaban transferencias incondicionales.

Son sustanciales los recursos que se transfieren automáticamente $\mathrm{o}$, al menos, no se condicionan a la productividad. Tanto la complejidad como la diversidad del financiamiento de los hospitales públicos impiden que la expansión de los recursos se vincule al logro de determinados niveles de eficiencia y desempeño, y debilitan así extraordinariamente tales incentivos. Respecto de la excesiva complejidad del financiamiento, cabe tener presente la relativa indivisibilidad de la producción hospitalaria frente a una diversidad de fuentes de financiamiento y a sus incentivos subyacentes, lo cual dificulta la transformación institucional y organizativa.

Sin embargo, algunos mecanismos de financiamiento contemplan incentivos al desempeño: entre ellos los contratos para atender a la población no asegurada, establecidos entre los fondos territoriales de salud y los hospitales públicos y privados, que condi-

\footnotetext{
${ }^{14}$ Situado fiscal es el nombre genérico del aporte fiscal de la nación.
} 
CUADRO 2

Colombia, sector salud oficial: Distribución de competencias y responsabilidades, después de la descentralización ${ }^{a}$

\begin{tabular}{|c|c|c|c|c|}
\hline Función & Nivel central o nacional & Nivel departamental & Nivel municipal & Hospital \\
\hline Financiamiento & ++ & ++ & ++ & + \\
\hline Rectoría, vigilancia y control & +++ & + & + & --- \\
\hline Nombramiento de directores & --- & $\begin{array}{c}++ \\
\text { (Niveles II y III) }\end{array}$ & $\begin{array}{c}++ \\
\text { (Nivel I) }\end{array}$ & --- \\
\hline Planeación e inversión & --- & ++ & ++ & ++ \\
\hline Definición salarial & +++ & --- & --- & --- \\
\hline Nombramiento y remoción & --- & $\begin{array}{c}++(*) \\
\text { (Servicios seccionales) }\end{array}$ & $+(*)$ & $+(*)$ \\
\hline Compra de insumos & + & ++ & ++ & +++ \\
\hline
\end{tabular}

Fuente: Cuadro elaborado por Londoño, Jaramillo y Uribe (1999).

a Los signos indican lo siguiente:

(*) Sujeto a leyes laborales y condicionado por convenciones colectivas.

+++ Plena competencia y responsabilidad.
++ Competencia y responsabilidad compartidas.

+ Mínimo espacio de competencias y responsabilidades.

--- Ausencia de competencia y responsabilidad. cionan el financiamiento a incrementos efectivos de la productividad y eficiencia, y que se han aplicado principalmente en Antioquia y Bogotá, con heterogéneas consecuencias financieras y de gestión. ${ }^{15}$

Los hospitales deben vender sus servicios a los asegurados, de suerte que su capacidad para generar recursos propios y tener una efectiva autonomía financiera está parcialmente condicionada por una variable crucial que escapa a su control: la ampliación del aseguramiento de la población. Así, en 1996 la venta de servicios ascendía a una quinta parte de los ingresos de los hospitales y de ella, casi la mitad era al régimen subsidiado. Las estimaciones de la ampliación de cobertura de ambos regímenes son polémicas. ${ }^{16}$

Por su parte, los entes territoriales y aseguradores, al incurrir en mora de pagos a los prestadores, han provocado déficit e iliquidez en un número importante de entidades de los niveles II y III. Resulta insólito

\footnotetext{
15 Desde experiencias exitosas en el Hospital El Tunal de Bogotá o el San Vicente de Paul en Medellín, pasando por la bancarrota de instituciones como el Hospital Lorencita Villegas, y llegando hasta profundas reestructuraciones como la del San Juan de Dios en Bogotá (Londoño, Jaramillo y Uribe, 1999, pp. 19 y 62).

16 Cabe señalar que la depuración de duplicaciones de datos que sobredimensionan la cobertura puede llevar a estimaciones incorrectas sobre el estancamiento o disminución de ésta (Colombia, Consejo Nacional de Seguridad Social en Salud, 2000, pp. 13-17 y 37; CIE, 2000, p. 7). Quienes aprecian un estancamiento desde 1998, lo atribuyen a impostergables ajustes macroeconómicos, al incremento del desempleo, cuestionamientos del régimen subsidiado y vacilaciones en el plano nacional y departamental (Jaramillo, 2000, pp. 101 y 88).
}

el creciente pasivo de las Aseguradoras del Régimen Subsidiado (ARS) con los hospitales, dado que ellas han tenido superávit en su manejo del régimen subsidiado: en 1996 , un $60 \%$ de los recursos de estas aseguradoras no fue utilizado (Jaramillo, 2000, p. 104).

La transición hacia la descentralización municipal también complica el acceso de los hospitales a recursos y con ello su desarrollo como ESE: el rezago organizativo de los municipios inhibe la descentralización hospitalaria, porque en aquéllos no certificados ${ }^{17}$ la cadena de financiamiento asociada al situado fiscal es tortuosa. ${ }^{18}$ Se teme asimismo que las trabas para la asignación de recursos puedan "premiar la pereza fiscal local", si recursos fiscales de la nación transferidos a través del municipio no llegan finalmente al sector salud (Jaramillo, 2000). O, por el contrario, se verifica que hay problemas de oportunidad en el flujo de recursos que fuerzan al nivel territorial a endeudarse. El enorme pasivo prestacional, ${ }^{19}$ aún no solucionado debidamente,

\footnotetext{
${ }^{17}$ Se ha establecido una forma de transición para la descentralización de recursos a los municipios. Aunque la distinción ha sido más bien discrecional, los municipios que no reúnen requisitos de desarrollo técnico, financiero e institucional para recibir transferencias automáticas reciben las transferencias de manera condicionada, por medio de sus respectivos departamentos.

${ }^{18}$ En ese caso, para que el hospital público pague los servicios a un prestador o los insumos a un proveedor, intervienen previamente el Ministerio de Hacienda y Crédito Público, el Ministerio de Salud, el Departamento y su Asamblea Departamental, el Municipio y su Consejo municipal, y la ARS respectiva (Londoño, Jaramillo y Uribe, 1999, pp. 11 y 50).

${ }^{19}$ Es decir, aquél acumulado con sus empleados por la previsión.
} 
también acrecienta la deuda (Londoño, Jaramillo y Uribe, 1999, pp. 23, 38 y 59).

En este marco multivariable, los estados financieros de los hospitales públicos exhibían en 1998 y 1999 toda una gama de situaciones: superávit, déficit o puntos de equilibrio. Para cubrir déficit se han destinado incluso recursos del Fondo de Solidaridad y Garantía que tienen otros propósitos. ${ }^{20}$

\section{El déficit regulatorio como obstáculo al desem- peño y a la eficacia global}

La regulación debiera posibilitar y supervisar la operación eficiente y competitiva del mercado, en consonancia con los principios del modelo de salud: universalidad, integralidad, descentralización, concertación, obligatoriedad, solidaridad, libre elección, gradualidad, eficiencia y calidad. Pero hay graves debilidades en materia regulatoria.

Por ejemplo, al no existir normas claras, han proliferado entidades aseguradoras que, debido a sus características y deseconomías de escala, posiblemente no reúnen condiciones de eficiencia. La existencia de 200 ARS por sí sola evidencia altos costos de transacción; de ellas tan sólo el $4 \%$ tiene más de 25000 afiliados, el $84 \%$ tiene entre 5000 y 25000 y un $8 \%$, menos de 5000 (Londoño, Jaramillo y Uribe, 1999, p. 48). Este fenómeno recuerda la hipertrofia, ineficacia y encarecimiento de la intermediación en salud en Argentina, asociadas, entre otros factores, a los altos costos administrativos y a la restricción de servicios de salud efectivos garantizados por las aseguradoras denominadas "administradoras de cápitas" (Sojo, 1997, p. 47).

Claros indicios de abuso de su posición dominante por parte de entes aseguradores hacen perentorio establecer reglas y sanciones. Así, se observa el "abuso por parte de algunos aseguradores, especialmente ARS, que actúan realmente como intermediarios costosos, en lugar de como aseguradores valiosos". Por ejemplo, hay ARS que simplemente absorben una fracción considerable del pago per cápita y trasladan el saldo a una segunda entidad intermediadora, que subcontrata a prestadores. O bien, cuando no existen relaciones de competencia entre aseguradores se ponen de manifiesto, además de demoras en los pagos, prácticas abusivas de imposición de tarifas a hospitales con débil capacidad negociadora, a veces en asociación con autorida-

\footnotetext{
${ }^{20}$ Como las subcuentas de enfermedades catastróficas y accidentes de tránsito, y la subcuenta de solidaridad.
}

des municipales (Londoño, Jaramillo y Uribe, 1999, pp. 23, 49 y 50). Ello además de que este pago per cápita, al ser un promedio general no ajustado por riesgo, promueve una selección adversa (Mora y Malabet, 1998).

Por otra parte, los atrasos en pagos a hospitales en que incurren las entidades aseguradoras del régimen contributivo y del subsidiado, llaman la atención sobre una grave falta de regulación que provoca problemas al sistema hospitalario público, cualquiera sea su desempeño.

Se critica la débil capacidad regulatoria del Ministerio de Salud en cuanto a establecer normas generales que unifiquen la dinámica descentralizadora. Se afirma que no existen lineamientos sólidos mínimos que respalden criterios a escala nacional sobre contrataciones, normas de calidad de la información o gestión financiera. Los atomizados criterios de los entes territoriales permiten afirmar que "antes que una reforma nacional, se puede plantear la existencia de múltiples reformas territoriales, con avances dispares y poco intercambio horizontal" (Mora y Malabet, 1998, p. 59).

Otra carencia regulatoria se da en torno a lograr equidad territorial en el acceso a la salud, y una adecuada integración vertical y horizontal de los niveles de atención, aspectos que están interrelacionados. La coordinación regional o territorial de la red de oferta de servicios está en manos de las direcciones regionales y municipales de salud, que deben velar por una buena capacidad resolutiva y relaciones complementarias entre los prestadores públicos y privados. Sin embargo, se sobrestimó la capacidad de respuesta de la oferta privada prestadora y aseguradora en entidades territoriales de menor desarrollo y tamaño: en economías con fuertes disparidades distributivas, el mercado atrae naturalmente la oferta privada, especialmente la de calidad, hacia los sectores de altos ingresos (Ocampo, 1996). Esto, unido a los problemas de las instituciones públicas, ha llevado a graves y costosos desequilibrios en la oferta territorial (Londoño, Jaramillo y Uribe, 1999, p. 63).

Desde ya emergen entonces las paradojas de un autofinanciamiento hospitalario librado a sí mismo, sin que la institución hospitalaria esté articulada en un sistema de referencia y contrarreferencia; para superarlas hacen falta regulaciones que bien pudieran insertarse en instrumentos de gestión como los contratos. Experiencias en Cataluña o más recientemente la de Costa Rica demuestran, por ejemplo, que es posible velar por la integración de los niveles de atención y por las redes de referencia y contrarreferencia mediante contratos de financiamiento vinculado a desempeño, 
con entidades públicas y con entidades privadas (Gallego, 1999, pp. 55-57, 76-77; 265; Franch, s.f.; Sojo, 1998, pp. 94 y 95).

Sin embargo, con contadas excepciones, ${ }^{21}$ la reforma acusa un inexplicable descuido de los factores epidemiológicos, de la promoción de programas preventivos, de la integración de los niveles de atención y de la conformación de redes de referencia y contrarreferencia. Como la reestructuración del hospital público no se diseñó en relación con la oferta territorial, sino de manera aislada, la gama de servicios que él brindaría se dejó librado a su criterio. La mayoría de estos hospitales aún no ha definido esa oferta de manera cabal y explícita. La responsabilidad por la referencia de pacientes quedó presuntamente en manos de las entidades aseguradoras de ambos regímenes y el seguimiento epidemiológico a cargo de los departamentos, pero hay carencia de una visión sistémica y de los instrumentos pertinentes.

Además, de manera análoga al comportamiento del sector privado, la necesidad de autofinanciamiento del hospital público propicia barreras de acceso a prestaciones para sectores vulnerables que no son rentables. Los hospitales públicos, inclusive los del nivel I, si bien al intentar adaptarse al nuevo entorno elaboraron instrumentos de gestión como la facturación y consideraron variables de rentabilidad, sesgaron su gama de servicios y descuidaron el perfil epidemiológico como uno de los elementos determinantes de sus acciones, con lo cual se deterioraron apreciablemente programas preventivos como vacunaciones, detección precoz de patologías y atención integral de determinadas enfermedades.

Estos factores, unidos a la segmentación de la vigilancia epidemiológica y a la fragmentación de los programas, llevaron a que la cobertura de las vacunaciones contra la tuberculosis, contra la difteria, tétanos y Pertussis (DTP) y contra la poliomielitis disminuyeran en los años de la reforma, incluso hasta niveles considerados ineficaces (Londoño, Jaramillo y Uribe, 1999, pp. 66, 70, 71; CIE, 2000). ${ }^{22}$ También están en

\footnotetext{
${ }^{21}$ El Departamento del Huila, por ejemplo, donde se promovió una redistribución de las atenciones en los tres niveles hospitalarios, reforzando el nivel I y concentrando las atenciones más especializadas en los otros dos (Londoño, Jaramillo y Uribe, 1999, p. 54). ${ }^{22}$ Este sesgo se manifiesta también en el crecimiento de los recursos humanos del sector salud. Los odontólogos exhiben la tasa más alta $(52 \%)$, seguidos de los médicos $(47 \%)$, los promotores (19\%) y los técnicos de saneamiento con 18\% (Londoño, Jaramillo y Uribe, 1999).
}

juego criterios de fondo, como el de redefinir el papel tradicional del hospital en las vacunaciones, cuyos costos disminuyen apreciablemente al realizarse desde otros niveles de complejidad. Por lo demás, los hospitales no cuentan con el financiamiento adecuado para cumplir esta tarea, que al no haber sido asumida cabalmente por las municipalidades u otros entes mostró caídas de cobertura. ${ }^{23}$

La descentralización tiene desafíos pendientes. La criticada invasión sectorial de la autonomía territorial con normas nacionales que definen detalladamente el uso de los recursos (Vargas y Sarmiento, 1998), en este plano no ha garantizado la integralidad de los programas preventivos ni la coherencia de la vigilancia epidemiológica con una perspectiva territorial y nacional. Se están elaborando normas para uniformar criterios, contenidos y acciones de promoción, de detección temprana y de prevención en torno a la "demanda inducida y de obligatorio cumplimiento", que trasciende la demanda pasiva del usuario (Colombia, Consejo Nacional de Seguridad Social en Salud, 2000, p. 27) y cuyo anclaje institucional aún no está definido.

\section{De las estrategias defensivas a la reforma de la gestión}

El status de las ESE es ambiguo y está tensado por dos lógicas: pueden regirse por el derecho privado y recurrir a cláusulas de contratación de la administración pública. En tanto que la contratación conforme al derecho privado permite convenciones colectivas de trabajo y la formación concomitante de sindicatos, los funcionarios públicos no pueden hacer convenciones colectivas.

El gerente y la junta directiva de una ESE pueden contratar personal no permanente, comprar insumos e invertir en equipamiento, y decidir sobre el uso de excedentes operacionales. Los excedentes se pueden destinar a bonificaciones para los empleados, a inversiones o a subsidios cruzados entre sus servicios. La compra de insumos, medicamentos o servicios de técnicos puede hacerse de acuerdo con el régimen privado. No obstante, la ley autoriza a la entidad pública a

\footnotetext{
${ }^{23}$ Preocupaciones expresadas por Juan Fernando Alviar, a cargo de la Dirección Operativa de Salud Pública de Rivaralda, en conversación en Santiago el 22 de mayo de 2001. En 1999 se amplió la cobertura de inmunizaciones mediante un programa ad hoc para adquirir vacunas con recursos del Fondo de Solidaridad y Garantía (Colombia, Consejo Nacional de Seguridad Social en Salud, 2000, p. 31 y siguientes).
} 
usar cláusulas de la contratación pública denominadas "exorbitantes", las que permiten, por ejemplo, poner fin unilateralmente a los contratos. ${ }^{24}$

La discrecionalidad en materia de contratación para enfrentar un marco de rigideces ha llevado a que la mayoría de los nuevos empleos en los hospitales no sean permanentes: en su mayoría corresponden a contratos temporales. Sólo un $18 \%$ de los nuevos empleos son de planta, lo cual ha dado lugar a una "planta paralela" en las instituciones, que ha subido de 3.000 a 10.000 personas y permite un manejo flexible del personal (Londoño, Jaramillo y Uribe, 1999, pp. 23 y 43).

Por su parte, la flexibilidad laboral de los funcionarios está acotada por el hecho de que el personal de planta continúa contratado bajo las categorías de empleados públicos y trabajadores oficiales, de conformidad con el régimen público de selección, nombramiento y contratación regido por las leyes laborales vigentes y convenciones colectivas, con altos beneficios extralegales. La legislación laboral es bastante rígida y los incrementos salariales los pacta el gobierno central a escala nacional para todo el personal de planta en los hospitales y centros asistenciales (Londoño, Jaramillo y Uribe, 1999, pp. 17-19, 60-66 y 88-90).

En casos exitosos de reorganización hospitalaria, como los de Antioquia, emergen tres factores cruciales: flexibilización oportuna de las plantas de personal, que permite racionalizar los gastos en ellas; fortalecimiento del liderazgo y de la capacidad de gestión de los equipos directivos, y un entorno en el cual se ha fortalecido el aseguramiento (Londoño, Jaramillo y Uribe, 1999, p. 65).

En ensayos de modificar incentivos en los hospitales públicos se ha recurrido a instrumentos como uso de contratos; mecanismos de rendición de cuentas (accountability); mayor autonomía en aspectos financieros y administrativos como la adquisición de insumos y la contratación de personal; retención de los ahorros de eficiencia para entregar bonos de productividad; sistemas de información para hacer el seguimiento del desempeño y la productividad; encuestas para medir la satisfacción de los usuarios; modificaciones de la composición de la planta del hospital y de sus jornadas, y sistemas de facturación. ${ }^{25}$ Salvo en tales ensayos, se ha innovado poco en las formas de contratación. No hay indicadores de desempeño generales sobre mejoras de eficiencia y equidad en los hospitales autónomos ni ha

\footnotetext{
24 Esta información nos fue suministrada por Iván Jaramillo.

25 Como las del Hospital Garcés Navas, el Hospital El Tunal y la Clínica del Niño Jorge Bejarano.
}

habido acuerdos sobre el uso de pagos prospectivos y de presupuestos históricos; más del $60 \%$ de los municipios está bajo investigación por desviación y uso indebido de recursos destinados a salud (Londoño, Jaramillo y Uribe, 1999, pp. 50 y 59).

Cuando la solidaridad y universalidad se promueven en un marco de competencia, la reforma de la gestión pública debe fomentar relaciones de efectiva competencia y de complemento entre los sectores público y privado, posibilitar que el sector público compita en costos y en calidad, y contribuir a un mejor diseño de la combinación público-privada. De allí que sea perentorio sistematizar los aspectos positivos y negativos de las experiencias llevadas a cabo para acometer, al menos gradualmente, la reforma de gestión del conjunto de la red hospitalaria.

No parece conveniente, por el contrario, aplicar estrategias de defensa y protección del sector público ante la competencia que posterguen o suplanten urgentes reformas de gestión, como lo hizo el Instituto de los Seguros Sociales (ISS): para propiciar su adaptación a la competencia dentro del régimen contributivo, en lugar de impulsar al mismo tiempo una profunda reforma en materia de gestión que elevara su eficiencia y eficacia, adoptó una estrategia eminentemente defensiva. Luego, se le otorgaron ciertas ventajas o privilegios protectores: pudo reunir las funciones aseguradora y prestadora; no se le exigió el cobro de copagos y se le autorizó a brindar un plan ampliado de beneficios sin que se aplicaran los períodos de carencias ${ }^{26}$ establecidos por la ley (Londoño, Jaramillo y Uribe, 1999, p. 47). Sin embargo, el iss ha presentado déficit y deterioros patrimoniales y, por la magnitud de su crisis, desde mediados de 1998 le fueron prohibidas nuevas afiliaciones.

Por otra parte, para dar mayor garantía y protección a la red pública y hacer más atractiva la prestación de servicios de salud a los más pobres, la Ley 344 de 1996 estableció que las ARs debían contratar un mínimo obligatorio de prestaciones con los hospitales públicos, equivalente al $40 \%$ de los recursos del régimen subsidiado. En algunas regiones del país ha habido rechazo de los hospitales o de sus sindicatos a convertirse en ESE y a renunciar al financiamiento por presupuesto histórico y se ha presionado por atar el régimen

\footnotetext{
${ }^{26} \mathrm{Al}$ contratar inicialmente un aseguramiento, existen los llamados períodos de carencia, que establecen una cotización mínima previa al derecho a demandar ciertos servicios y beneficios y durante los cuales no se puede disfrutar de éstos. Tales períodos de carencia se establecen a fin de promover y garantizar la estabilidad de las cotizaciones.
} 
subsidiado a la red hospitalaria pública. Los hospitales del nivel I han sido los más reticentes a convertirse en ESE. La transformación de los subsidios a la oferta en subsidios a la demanda se congeló en respuesta a la iliquidez de algunos hospitales públicos (Jaramillo, 2000, pp. 37, 38 y 58).

A fines de 1998 cerca de un tercio de los hospitales de alta y mediana complejidad mostraban reticencia a la modernización. No habían adaptado su estructura orgánica al nuevo marco legal y, en muchos casos, estaban a cargo de direcciones interinas que, por su carácter inestable, no podían garantizar un proceso de transformación y mejoramiento. Así, algunas instituciones hospitalarias debieron cerrar, agobiadas por antiguas estructuras inflexibles y muy ineficientes que les impidieron insertarse en el nuevo modelo. Otras, ante la posibilidad de ser liquidadas, han presionado para obtener incrementos de recursos que no dependan de su productividad (Londoño, Jaramillo y Uribe, 1999, pp. 49 y 64).
Hay que resaltar también aquellos cambios de gestión que son importantes para apuntalar otros aspectos de la reforma. Por ejemplo, para afinar el costo de las unidades de capitación y avanzar en los precios negociados es indispensable contar con registros confiables sobre actividad, costos y calidad, así como sistemas de facturación que fortalezcan la capacidad gerencial.

Muchos de los retos se pueden encarar en la medida en que se logren consensos. En este tema, como en el de la descentralización, es necesario reconocer la realidad política del proceso para lograr consensos en torno a la forma de encarar nuevos desafíos y problemas. De igual manera, la fragmentación de responsabilidades entre los diferentes niveles gubernamentales y la complejidad o falta de claridad de la normativa son a menudo el producto de negociaciones precarias entre intereses contrapuestos que se ven afectados (Chiappe, 1999, p. 3).

\section{IV}

\section{Argentina: el gran abanico de la descentralización hospitalaria}

En Argentina, la reforma ha tenido dos ejes. Uno ha sido el fomento de la libertad de elección y de la eficiencia y equidad de las aseguradoras de salud, conocidas como obras sociales; cabe señalar que la hipertrofia de la intermediación financiera a cargo de las denominadas "administradoras de cápitas" ha llevado recientemente a legislar sobre esta materia. El otro eje ha sido la autogestión hospitalaria, llamada a elevar la eficiencia ante desafíos importantes planteados por estructuras hospitalarias sobredimensionadas, subsidios cruzados hacia las obras sociales, sistemas inadecuados de referencia y contrarreferencia, arraigadas prácticas tradicionales de gestión e indefiniciones sobre la forma de financiar algunas funciones - como las docentes - en el marco de la autogestión (Sojo, 1997; Tafani, 1997).

\section{Espíritu e instrumentos de la reforma hospita- Iaria}

En 1993, un decreto instauró el marco jurídico general para la autonomía hospitalaria, que concibe al hospital público de autogestión en un sistema de redes de servicios de salud centradas en el hospital, que deben articular y coordinar los servicios de salud que suministran los prestadores públicos y privados en un sistema de cobertura universal y obligatoria, con una estructura pluralista, ${ }^{27}$ participativa y de administración descentralizada. Estipuló además que las obras sociales debían

\footnotetext{
${ }^{27}$ La idea de la participación pluralista está presente en la conformación de los directorios. Por ejemplo, en el caso de una aseguradora pública como el Instituto del Seguro Provincial de Salud de Salta, el directorio está integrado por un presidente y cinco directores. El presidente es designado por el Poder Ejecutivo a propuesta del Ministerio de Salud Pública. Los directores representan a los prestadores públicos, a los prestadores privados, a las obras sociales con mayor cantidad de beneficiarios de la provincia, a los municipios con autonomía institucional y a los asegurados. El ministerio propone al Poder Ejecutivo los candidatos que ha seleccionado de las ternas propuestas por las entidades pertinentes y está presente en la conformación de la Comisión Permanente de Concertación, presidida por el secretario de servicios de salud o su delegado, e integrada por representantes del directorio del Instituto del Seguro Provincial de Salud y de las entidades representativas mayoritarias de los prestadores en el ámbito provincial (Argentina, Gobierno, 1998b).
} 
pagar a los hospitales los servicios recibidos por sus beneficiarios, y estableció un mecanismo para deducir automáticamente, de las transferencias a dichas obras por concepto de cotizaciones, las deudas que ellas contrajeran con los hospitales.

La separación de funciones se ha hecho de conformidad con las realidades provinciales, y su regulación se concibe, en ciertos ámbitos, como descentralizada. Con esto se corre el riesgo de que la regulación sea fragmentaria y atomizada, carente de un marco normativo a escala nacional que respalde los criterios, lineamientos y estándares mínimos aplicables a las relaciones de contratación entre aseguradores y prestadores, así como a la calidad de las prestaciones o de la gestión.

Por ejemplo, en el caso de Salta, ${ }^{28}$ el directorio de la entidad aseguradora dicta las normas que regulan las distintas modalidades de sus relaciones contractuales con los prestadores e interviene en la elaboración y actualización de los instrumentos utilizados para la regulación. La Comisión Permanente de Concertación debe elaborar las normas, procedimientos y estándares de utilización a que debe ajustarse la prestación de servicios, y fijar las modalidades y valores de retribución. Esto último podría difuminar la línea divisoria entre la función financiera y la función prestadora, y llevar a confundir la concertación en torno a estos temas con su regulación, potestad que debiera permanecer en manos de la entidad compradora.

La reforma de gestión contempla mejoras de procesos, como por ejemplo la implantación de un registro único de salud (RUS) en el caso de Mendoza, bases de datos que permitan identificar la población atendida, la entrega a cada usuario de una credencial que lo vincule con los centros médicos pertinentes y la mantención de su historia clínica actualizada. También en ese caso la elevación de los estándares de calidad mediante las Cartas de Compromiso con el Ciudadano, que difunden el tipo de prestaciones y los estándares de calidad (Neirotti, 1999).

Entre los elementos que han favorecido los consensos en torno a la reforma hospitalaria entre actores influyentes se menciona tanto la capacitación de los profesionales involucrados como tempranas actividades formativas sobre la reforma de los hospitales y de las obras sociales. ${ }^{29}$ También experiencias piloto con

28 Es el caso del proyecto de ley orgánica del Instituto del Seguro Provincial de Salud de Salta (Argentina, 1998b).

${ }^{29}$ Puede consultarse la documentación respectiva en http:// www.msal.gov.ar/pressal fuerte apoyo al desarrollo organizativo en la ciudad de Buenos Aires, en las provincias de Buenos Aires y Mendoza y, con menor intensidad, en otros lugares (Abrantes, por publicarse). ${ }^{30}$

Los hospitales que se acogen al régimen de autogestión pueden establecer contratos con aseguradores y con prestadores de los servicios que la entidad hospitalaria no provee. Dentro de la planta de personal, pueden designar, promover y transferir empleados. Pueden ejercer cierto control sobre su plan operativo y presupuesto anual. Pueden vender servicios, cobrar copagos según grupos de ingreso y disponer de estos ingresos, al igual que de aquellos pagados por las obras sociales, para dedicarlos a incentivar la productividad del personal, a inversiones o a mantenimiento. Se está ensayando el financiamiento independiente de las funciones de capacitación y educación realizadas por los hospitales.

\section{Los contratos de gestión de los hospitales}

Los contratos de gestión para el financiamiento hospitalario, que deben sustituir al financiamiento por presupuestos históricos, se están implantando gradualmente desde 1998, con características de "ficción jurídica”, para posibilitar el aprendizaje. Debido a la descentralización, los hospitales ya pertenecían a las provincias y a algunas municipalidades. Por ello, la autogestión hospitalaria ha adquirido matices diversos de uno a otro lugar, y no se implantó un modelo único de contrato de gestión: se desea adaptarlo a la realidad de cada provincia, según la forma en que se haya organizado en ella la separación de funciones (Sánchez de León, 1998, p. 50). ${ }^{31}$

Por ejemplo, la perspectiva de cambio es más radical en Salta, ya que el contrato debe contribuir a transformar la modalidad de asignación de recursos en lo que en Chile y Colombia se ha denominado subsidio a la demanda. Mientras que en La Pampa, el énfasis se puso en los incentivos económicos que podían redistribuirse en el hospital de autogestión a partir de la facturación a las obras sociales. Y en Santa Fe, se trata de consolidar un modelo de descentralización que

\footnotetext{
${ }^{30}$ Los hospitales piloto recibían un equipo residente de consultores en administración de hospitales, que en conjunto con la administración del hospital definía su misión y objetivos, desarrollaba un plan de mediano plazo y coordinaba consultorías cortas sobre temas específicos (PRESSAL, 1998).

${ }^{31}$ Véase ejemplos de propuestas teóricas y de experiencias provinciales en PRESSAL (1998).
} 
funciona desde hace varias décadas, regulándolo con el contrato (PRESSAL, 1998, p. 11). En cada provincia se han elegido algunos hospitales para trabajar con contratos de gestión (ibíd., p. 32).

Los contratos de gestión comprenden a veces metas bastante acotadas, con índices de actividad y eficiencia (promedio de días de estada, número de egresos, número de cirugías) e índices de calidad (días de estada prequirúrgica, tiempo de espera en prediagnóstico y laboratorios, formación de comités de infecciones hospitalarias). En cuanto al personal, lo que se busca generalmente es disminuir el ausentismo e impulsar la capacitación (Argentina, Gobierno, 1998a; Neirotti, 1999; Abrantes y Dias Legaspe, 1999; Abrantes, por publicarse).

Otros contratos contemplan una gama mayor de aspectos relativos a la mejora de procesos y a la inserción en la red de prestadores, asemejándose a los complejos compromisos de gestión de Costa Rica. Así, en el caso de La Pampa, con énfasis distintos en cada hospital, los contratos abarcan: cumplimiento de protocolos diagnósticos y terapéuticos; procedimientos de referencia y contrarreferencia; capacidad de resolución concordante con el nivel de complejidad; adecuación de historias clínicas y del sistema de registros; consolidación de un médico orientador - una suerte de gatekeeper-; mediciones de satisfacción del usuario; programas educativos para la comunidad; cumplimiento de programas preventivos (PRESSAL, 1998, p. 40).

Los deficientes sistemas de facturación están siendo mejorados. Se ha incrementado la recuperación de costos ante las aseguradoras, lo que permite ofrecer bonos de desempeño individual que en algunos casos pueden hasta duplicar el ingreso de los médicos. Al estar la reforma hospitalaria inserta en un marco de disciplina fiscal vinculado con los proyectos de reforma provincial, las provincias han restringido a los hospitales su autonomía financiera y la capacidad de contratar personal. El margen para los incentivos ha dependido esencialmente de las ganancias de eficiencia, de los ingresos por servicios prestados a las aseguradoras, de los copagos y de las posibilidades de reducir la proporción de gastos en personal para crear holguras financieras (Abrantes, por publicarse).

Como ya se ha destacado, el financiamiento del sistema de incentivos a partir de lo que se factura y cobra en seguridad social, aunque inicialmente tal vez aliente la producción, lleva implícito un incentivo de selección adversa contra la población no asegurada, lo que revela que, en aras de la equidad, es importante diseñar presupuestos con componentes flexibles destinados a incentivos (PRESSAL, 1998, p. 51). También se ha señalado que, en ocasiones, los complementos salariales financiados con cobros a los diferentes aseguradores no se han vinculado con incentivos al desempeño; por ejemplo en Mendoza, éstos se otorgaban en 1998 a profesionales y no profesionales y se excluía a los directivos, pero en un esquema de distribución de "más por lo mismo" (ibíd., p. 38).

\section{Los grados de autonomía hospitalaria}

En lo que toca a los grados de autonomía de los hospitales, es posible distinguir a grandes rasgos tres situaciones básicas en el territorio. ${ }^{32} \mathrm{En}$ las provincias de Entre Ríos, Formosa, La Rioja, San Luis, Santiago del Estero y Tucumán, los hospitales siguen siendo financiados en su mayoría por presupuestos históricos, y su autonomía es muy restringida. En Salta y San Juan, en cambio, los hospitales tienen carácter de consorcios públicos (trusts), están regidos por el derecho público y privado, tienen un manejo autónomo del personal y de los activos y disponen de los recursos que generan.

Se han establecido contratos de gestión entre los hospitales y las provincias y dentro de los hospitales; los contratos incluyen algunos indicadores de desempeño relativos a eficiencia y calidad del servicio. Los hospitales deben competir con otros prestadores públicos y privados, y la clientela es segmentada: los asegurados y quienes pagan los servicios, por un lado, y los pobres no asegurados que reciben atención gratuita, por otro. Los directores tienen contratos a plazo fijo, independientes del ciclo político. Los ingresos propios pueden dedicarse a inversiones, mantenimiento e incentivos de desempeño para el personal. En Salta, Tucumán y San Juan, a partir del 2003, los pobres y los no asegurados deberán poder elegir entre proveedores públicos y privados.

En una situación intermedia están los hospitales más importantes de Corrientes, Catamarca, La Pampa, Mendoza y Río Negro que, financiados por presupuestos históricos, tienen consejos administrativos y técnicos que nombran a los directores, y han adquirido algún grado de autonomía sobre los insumos no vinculados a recursos humanos. Pueden retener hasta un $80 \%$ de los ingresos por servicios a asegurados para destinarlos a incentivos de desempeño, inversiones y mantenimiento. En materia de personal, si bien pueden promover empleados e incentivar jubilaciones

\footnotetext{
32 Distinción realizada por Abrantes (por publicarse).
} 
anticipadas, no pueden contratar ni despedir empleados. Aunque los contratos contienen indicadores de desempeño, sólo en Río Negro su cumplimiento se vincula con bonos al desempeño individual. En las provincias de Buenos Aires, Entre Ríos y Santa Fe, a pesar de contar con una legislación similar, la dinámica ha sido más lenta o poco consistente.

El Hospital Nacional Pediátrico Dr. Juan Garraham de Buenos Aires, de nivel III (de referencia), y el
Hospital Clínico José de San Martín, hospital docente de la Universidad de Buenos Aires, son empresas públicas que tienen control total de sus presupuestos e ingresos propios, y responsabilidad total por las deudas que contraigan, aunque recientemente el San Martín logró que se le financiara una significativa deuda acumulada. Ambos destacan por los ingresos propios que están logrando para inversión y mantenimiento, que ascienden a casi un tercio de sus presupuestos.

\section{V}

\section{Compromisos de gestión en un escenario eminentemente público: Costa Rica ${ }^{33}$}

En medio de una avanzada transición epidemiológica y demográfica, Costa Rica, que ha logrado una efectiva cobertura universal en salud de la población mediante un sistema de salud público solidario, ambiciona mejorar la eficiencia y eficacia de las instituciones públicas que prestan servicios de salud. La reforma tiene como eje la introducción de compromisos de gestión y se ha ejecutado en forma gradual desde 1996.

Se pretende superar el patrón implícito y explícito de gestión tradicional de la Caja Costarricense de Seguro Social (CCSs), entidad que reúne las funciones aseguradora y prestadora, y su sistema de incentivos negativos subyacente, propio del financiamiento tradicional que no considera desempeño: desigual oferta de servicios que ha respondido a la capacidad de presión de cada centro; indiferencia hacia la insatisfacción de los usuarios; agendas médicas que dan lugar a una suerte de mercado cautivo en manos de los especialistas; control administrativo del presupuesto y desconocimiento de los costos de los servicios; remuneraciones determinadas por la antigüedad y ausencia de evaluación del desempeño de los funcionarios; alto grado de ausentismo y de sustituciones e incapacidades, y autorregulación de los profesionales en el ámbito de la gestión clínica.

\section{Los instrumentos de la reforma}

Desde 1997 la cCss ha separado internamente sus funciones financiera y prestadora de servicios, y ha arti-

${ }^{33}$ Véase un estudio detallado en Sojo (1998 y 1999b). culado una función compradora, que aún está en etapa de gestación y decantación respecto de la función financiera. De manera gradual y selectiva se han implantado los compromisos de gestión con los hospitales y áreas de salud, hasta llegar a la totalidad de ellos en el año 2000, sin que los recursos destinados a la función de compra se hayan incrementado de manera correlativa.

Este cuasi mercado está sujeto a mucha regulación en términos internos, ya que el nivel central de la CCss reúne los poderes recaudadores directos, de regulación, de fijación de reglas y de nombramiento de puestos claves. Pero implica fuertes negociaciones internas, ya que los acuerdos fundamentales se toman en la Junta Directiva de la ccss. La función compradora es monopsónica, ya que no se establecen microcompradores o mesocompradores, en tanto que la función prestadora se desconcentra entre múltiples entidades de la ccss y de las cooperativas.

Se está impulsando un nuevo modelo de financiamiento, que tiene como principios rectores la solidaridad, la universalidad y la equidad. El modelo de financiamiento teórico contempla un componente presupuestario variable condicionado al logro de los objetivos y metas, que asciende a un $10 \%$ del presupuesto total y se divide paritariamente entre un fondo de incentivos y un fondo de compensación solidaria que compensa imprevistos en la ejecución presupuestaria. En el primer nivel de atención, el financiamiento histórico deberá evolucionar hacia un pago per cápita ajustado al patrón de uso de servicios según tasas de mortalidad infantil, sexo y estructura de edades de la 
población atendida, para revertir las desigualdades vigentes en la asignación territorial de recursos. En el segundo y tercer nivel de atención, la actividad global del hospital en una primera fase se desglosa en cuatro áreas: hospitalización, atención ambulatoria en consultas especializadas y no especializadas, urgencias, y programas asistenciales especiales, docentes y de investigación. Para ellas se establece una unidad de producción homogénea, que consiste en un coeficiente estándar de equivalencia denominado unidad de producción hospitalaria (UPH). La UPH está muy estrechamente relacionada con la estancia hospitalaria, y sus valores se estipulan en una tarifa que es invariable para el período de vigencia del compromiso. En estos niveles se pretende avanzar después hacia el pago por casuística o combinación de patologías atendidas (case $m i x$ ) o de grupos relacionados de diagnóstico (GRD).

Para iniciar el cambio, se asumieron los presupuestos históricos y, con datos de 1994, se construyó una función de producción. Se inició desde entonces una etapa de marcha blanca, en la cual la entrega de recursos aún no se ha vinculado al cumplimiento de los compromisos y al nuevo modelo de financiamiento.

\section{Paradojas de la complejidad de los contratos}

La medición de desempeño que orienta estos compromisos da lugar a innovación en los procesos, que puede contribuir a sistematizar la prestación de servicios, dilucidar aspectos específicos de su eficacia, reestructurar las organizaciones prestadoras y modificar su cultura de gestión. También asigna importancia a la creación y mantención de registros confiables sobre actividades, costos y calidad, y de sistemas de información que puedan fortalecer la capacidad de gestión. Apuntala asimismo el uso de instrumentos interesantes y de gran potencial, como los protocolos clínicos. Los contratos son específicos para las áreas de salud, y para el segundo y tercer nivel de atención, aunque se observa una convergencia de los aspectos considerados. ${ }^{34}$

A diferencia de Colombia, donde como vimos se ha descuidado la salud preventiva y los sistemas de referencia, estos contratos promueven el mejoramiento de la organización del sistema de salud y de la prestación de servicios, alentando especialmente la interacción de los tres niveles de atención. En cuanto a las áreas de salud, premian su capacidad de resolución y

\footnotetext{
34 Véase un tratamiento detallado de las características de estos compromisos y del modelo de financiamiento en Sojo (1998).
}

la disminución de referencias e incentivan acciones de prevención y promoción que a mediano y largo plazo permitan disminuir la morbilidad y mortalidad y consolidar condiciones de salud deseables. En lo que toca a los hospitales, reglamentan un sistema de referencias y en algunos casos especifican una red hospitalaria que deberá ser consolidada. Promueven que el segundo nivel de atención realice actividades de interconsulta y de capacitación para el primer nivel de atención, y que se verifique la cobertura real de la población adscrita.

La calidad de la atención, concebida como un proceso continuo de mejoramiento, tiene también un espacio importante. La medición de calidad está presente en indicadores que remiten a la eficacia de las prestaciones médicas (complicaciones de la salud de pacientes, trayectoria y causas de la tasa de mortalidad, etc.), o en procedimientos para asegurar el uso adecuado de los medicamentos, mejorar los expedientes individuales de salud o controlar las infecciones intrahospitalarias. Hay preocupación por mejorar aspectos relacionados con la oportunidad de la atención y el acceso a ella con miras a optimizar el uso de recursos, para lo cual se han establecido algunos índices de eficiencia (reducción de listas de espera, resolución de urgencias, mejor uso de la capacidad instalada - por ejemplo, de los quirófanos-, disminución del ausentismo médico, agilización de servicios de apoyo como el de farmacia). Se han adoptado medidas orientadas a identificar procesos y responsabilidades funcionarias, y mecanismos para conocer la satisfacción de los usuarios y resolver reclamos.

Aunque se ha avanzado en la creación de condiciones para que la facturación sea viable, lo que es esencial para el nuevo modelo de financiamiento, éstas aún no han sido aplicadas. Se han ido uniformando los criterios de evaluación y se han refinado criterios para tipificar la producción y para depurar el presupuesto de producción según las actividades de los prestadores. $^{35}$

Sin embargo, la variedad cada vez mayor de indicadores utilizados en los contratos y su amplia gama

\footnotetext{
${ }^{35}$ Por ejemplo, en relación con los hospitales, se ha considerado el grado de comparabilidad de los centros y se han segregado para la asignación cuatro conjuntos de actividades: a) elemento asistencial, que se plantea como comparable y medible en UPH; b) actividades especiales claves, tales como las del San Juan de Dios en quemados, del Calderón Guardia en trasplante de hígado o del México en trasplante de corazón; c) actividades extraordinarias, como combatir el dengue o el cólera; d) inversiones, para lo cual antes no se establecía un financiamiento sistemático. Entrevista con René Escalante, gerente de la División Administrativa de la cCss, el 10 de diciembre de 1998.
} 
de objetivos podrían conspirar contra su aplicación, dificultar una evaluación que trascienda lo cuantitativo para adentrarse en identificar las condiciones que posibilitan o no el cumplimiento, y significar excesivos costos de transacción. Esto apunta a la necesidad de jerarquizar indicadores, limitar su número y velar por su continuidad, para poder consolidar los cambios en los procesos y en los sistemas de información.

Por lo mismo, habría que compactar los objetivos y metas. El formato de los compromisos, la amplitud de la gama de aspectos e indicadores y el hecho de que la transferencia de recursos no se haya subordinado aún al cumplimiento, asemejan los contratos en cierto sentido a una planificación por objetivos, que sedimenta o cristaliza algunas prioridades y aspectos organizativos y de prestación de servicios que se quiere exigir a los prestadores. Posiblemente esto se relacione también con la gradualidad del proceso, opción que llevó a una definición "conservadora" de los productos que se comprarían en una primera etapa: en términos cuantitativos, al asumir inicialmente los presupuestos históricos, y también en la tipificación por factores de esos productos, para determinar tanto los objetivos como los indicadores por evaluar (Guzmán, 1999, p. 60).

Si bien esa opción tal vez contribuyó a evitar el caos en las unidades al garantizar la coexistencia de elementos tradicionales que se vinculan con la reforma mediante los contratos, podría desembocar en una complejidad excesiva de los compromisos, que sea difícil de manejar a lo largo del tiempo, que dificulte la evaluación y cuyos altos costos de transacción, traducidos por ejemplo en la información que se debe pedir a los proveedores, lleven al formalismo o la letra muerta.

Implantar el financiamiento por capitación, por casuística o combinación de patologías atendidas, o por grupos relacionados de diagnóstico (GRD) permitirá evolucionar hacia un conjunto de compromisos que vele esencialmente por la eficacia y eficiencia de las prestaciones. Otros aspectos de la reforma de la gestión, como el afianzamiento del uso de la medicina basada en la evidencia, podrán vincularse con otros instrumentos que se integran a actividades irrenunciables, como la vigilancia epidemiológica. Los aspectos organizativos y productos intermedios, sin quedar excluidos, indudablemente deberán acotarse en los compromisos.

\section{El asidero jurídico}

La solidez legal de los contratos es fundamental, ya que determina, entre otros aspectos, la posibilidad de apli- car sanciones efectivas en caso de incumplimiento, las formas de resolución de conflictos dentro del mercado, el rango de las autoridades involucradas y los mecanismos previstos para enfrentar las omisiones e imprevisiones del contrato y resolver disputas (Walsh, 1995).

Los contratos de gestión de la ccss obtuvieron su primer asidero legal cuando fueron aprobados por la Junta Directiva de la institución. Pero se trataba, en términos jurídicos, de "cuasi contratos", ya que los hospitales y las clínicas no tenían personalidad jurídica propia. Un paso crucial para su solidez legal fue la Ley de desconcentración de los hospitales y las clínicas de la cCss, que convirtió el compromiso de gestión en el instrumento que articula y delimita tal desconcentración al determinar que los hospitales y las clínicas disfrutan de una "personalidad jurídica instrumental" para el "manejo presupuestario, la contratación administrativa, la conducción y la organización de los recursos humanos dentro de las disposiciones legales aplicables, los límites fijados por la Caja y el compromiso de gestión". Según nos aclaró su gestor, ${ }^{36}$ la personalidad jurídica instrumental es una figura más fuerte que la que tendría un ente desconcentrado, pero menor que la de una entidad descentralizada, ya que se ejerce estrictamente en los campos determinados por la ley y delimitados por el compromiso.

La Ley de desconcentración determinó también que las entidades serán administradas por el director, que deberá actuar conforme a los objetivos y obligaciones señalados en el compromiso de gestión, los reglamentos generales y los lineamientos de política que emita la ccss.

Pero la realidad siempre ofrece resistencia a los cambios, y en este caso la reglamentación de la ley refleja reacciones renuentes a las modificaciones de las reglas. Los cambios jurídicos han sido promovidos desde la presidencia ejecutiva de la cCss, que conduce el proceso sin un plazo determinado, buscando que no sea traumático. Pero las expectativas e interpretaciones del alcance de la ley no son homogéneas entre distintas instancias de la cCSs, donde predomina una interpretación limitada del proceso en términos de desconcentración administrativa, mientras que los prestadores tienen expectativas de lograr una elevada autonomía a muy corto plazo. Los reglamentos están más cercanos a la visión restrictiva de la desconcen-

\footnotetext{
${ }^{36}$ Entrevista del 7 de diciembre de 1998 con Rodolfo Piza Rocafort, presidente ejecutivo de la ccss.
} 
tración administrativa que a la descentralización de competencias y la autonomía de gestión (Guzmán, 1999, p. 82).

Están pendientes también temas fundamentales para consolidar un marco jurídico coherente con las nuevas formas de evaluación del desempeño en lo que respecta a los recursos humanos. Debieran modificarse los estatutos de los servicios médicos y de los servicios de enfermería que rigen a los profesionales en sus colegiaturas y que determinan su reclutamiento y evaluación a través del sistema del servicio civil. ${ }^{37}$ La regulación de las profesiones mediante tales estatutos obstaculiza su gestión en el seno de la CCss: entre otros aspectos, origina conflictos de supervisión, dificulta el desarrollo efectivo de las tareas y promueve una actitud gremialista de los funcionarios (Ortiz y Sequeira, 1998, pp. 99 y 100).

\section{El desempeño funcionario}

La presencia preponderante de la profesión médica y de personal paramédico determina estrechamente la naturaleza misma de los servicios provistos, y los nuevos sistemas de incentivos modifican la manera en que se cristaliza su poder y su margen de maniobra. Para echar las bases de relaciones de confianza dentro de un nuevo modelo de gestión y para realizar un adecuado seguimiento del desempeño funcionario, es perentorio modificar los procesos de reclutamiento y selección de personal y las regulaciones sobre su permanencia que están vigentes en la ccss.

La estabilidad funcionaria ajena al rendimiento, la carrera funcionaria condicionada por la antigüedad y no por el mérito, el pacto de atender de cuatro a cinco pacientes por hora, los tortuosos procesos para despedir a un funcionario ${ }^{38}$ y la imposibilidad de elección médica por parte de los pacientes, configuran una tenaza que impide modificar a cabalidad esta situación y que, en general, dificulta modernizar la gestión de los recursos humanos de la CCSS.

Es preciso modificar los criterios que rigen la entrada y permanencia en el servicio público, ya que la inflexibilidad de las contrataciones es, sin duda, un elemento crucial que puede ser un obstáculo a la innovación en la gestión. Se debe promover el acceso a los cargos de planta por concurso; evaluar la carrera funcionaria para poder determinar promociones y remuneraciones; simplificar los procedimientos para despedir funcionarios, unificar las formas de contratación. Los ahorros en eficiencia y productividad así logrados podrían contribuir a una mejora de las remuneraciones asentada en los nuevos criterios. En aras de la equidad, se tendrá que velar por la presencia equilibrada en todas las localidades de los recursos humanos necesarios.

Por otra parte, actualmente se está ampliando el espectro de prestaciones privadas con financiamiento de la CCss, para acortar listas de espera en especialidades. En este ámbito, cabe velar porque el trasvasije de profesionales entre ambos sectores no conduzca a conductas de riesgo moral entre los profesionales de la CCSS, como la disminución intencional de su productividad o el descuido de tareas como el adecuado mantenimiento de los equipos. Al respecto preocupa que esta apertura pueda consagrar bolsones de ineficiencia en las prestaciones de la CCSS, cuando, por el contrario, debiera contribuir a acortar las listas de espera. La apertura tampoco debiera conducir a limitar las inversiones en infraestructura y equipo de la cCSs, lo que causaría una solapada restricción de las prestaciones públicas y posiblemente una escalada de costos, si los precios pagados a los privados excediesen los que debería alcanzar la cCss en condiciones de eficiencia. Por otra parte, es preciso impedir la introducción de copagos (por ejemplo, para obtener prestaciones más expeditas en el sector privado) que socavarían la solidaridad del sistema.

37 Véase Universidad de Costa Rica (1998), citado por Ortiz y Sequeira, 1998, pp. 36 y 37.

${ }^{38}$ Es preciso simplificar a nivel nacional los procedimientos para despedir funcionarios. Actualmente existen las instancias del debido proceso, la apelación, la comisión local, la comisión central de relaciones laborales. El problema está en que se requiere un proyecto de ley para regular este aspecto y se debe tratar de uniformar la forma de contratación para los diversos sectores. Estos son algunos retos señalados por el Dr. Elías Jiménez, entonces director general del Hospital Nacional de Niños, en entrevista del 5 de febrero de 1998. 


\section{VI}

\section{A modo de conclusión}

Las reformas en salud efectuadas en la región, al hacer hincapié en el aseguramiento y el financiamiento, no siempre han tratado adecuadamente las variables organizativas e institucionales conexas. Los cambios en la gestión se han esbozado en el seno de sistemas diversos en cuanto a solidaridad y universalidad. En Chile se observa el mayor rezago en lo que se refiere a modificaciones del financiamiento y a corregir las debilidades de los compromisos de gestión. En Colombia, donde quizá donde se ha avanzado más en estructurar un nuevo sistema de financiamiento y reglas para él, la financiación hospitalaria adolece de una complejidad excesiva y sufre los efectos negativos de la intermediación financiera. Aunque el país exhibe logros en experiencias piloto, se observa un relativo descuido en materia de gestión en la generalidad de los hospitales y una débil inserción de éstos en redes de referencia y contrarreferencia. En Argentina, de la reforma hospitalaria resaltan los variados matices de la autogestión de los hospitales, al haber surgido en un contexto descentralizado; está sobre el tapete regular la selección de riesgo, mejorar la medición del desempeño para la entrega de incentivos, avanzar hacia la autonomía financiera y efectuar ajustes para superar el sobredimensionamiento. En Costa Rica los cambios en el financiamiento aún están en una fase experimental; son interesantes los compromisos de gestión, por los cambios que implican en materia de procesos, descentralización y mejoras de la red institucional, aunque su creciente complejidad puede atentar contra sus objetivos.
Abrantes, Alexandre (por publicarse): Contracting public health care services in Latin America, en Preker y Harding, Innovations in Health Care Delivery.

Abrantes, A. y Alberto Días Legaspe (1999): Contracting public health care services in Latin America, ponencia presentada en el First Europe and Latin America and the Caribbean Forum on Health Sector Reform, Banco Mundial, París, mayo.

Argentina (1998a): Anexo. Modelo de contrato de gestión. Estructura base, borrador de trabajo.

Argentina, Gobierno (1998b): Proyecto de ley orgánica del Instituto del Seguro Provincial de Salud de Salta, enero.

Bach, S. (1999): Trends in European health sector reform: Implications for human resource management, ponencia presentada en la Reunión Constitutiva del Observatorio de los recursos humanos en las reformas sectoriales de salud, Organización Mundial de la Salud/Organización Panamericana de la Salud (OMS/OPS), Santiago de Chile, junio.

Baeza, C. y otros (1998): El sector de la salud en Chile: un diagnóstico compartido, Santiago de Chile, diciembre.

Bartlett, W. y J. Le Grand (1993): The theory of quasimarkets, en J. Le Grand y W. Bartlett, Quasimarkets and Social Policy, The Macmillan Press, Londres.

CEPAL (2000): Equidad, desarrollo y ciudadanía, LC/G.2071, Santiago de Chile.

Chiappe, C. (1999), Elementos de análisis para una estrategia educacional de Colombia, Washington, D.C., Banco Interamericano de Desarrollo (BID), Departamento de Desarrollo Sostenible, Recursos Humanos y Desarrollo Social, División de Programas Sociales.

Chile, Ministerio de Salud (1998a): Estrategias innovadoras en salud. La reforma programática y financiera chilena, Santiago de Chile, abril.

(1998b): Políticas y estrategias innovadoras en salud. Reforma programática 1998, Santiago de Chile, agosto.
CIE (Centro de Investigaciones Económicas) (2000): Monitoreo del sistema de salud en el Departamento de Antioquia, Medellín, Colombia, Universidad de Antioquia.

Colombia, Consejo Nacional de Seguridad Social en Salud (2000): Informe anual del Consejo Nacional de Seguridad Social en Salud a las comisiones séptimas del Senado de la República y Cámara de Representantes, Santafé de Bogotá, julio.

Consultora ASENSA, Asesores en Salud (s.f.): Consultoría para el proyecto de fortalecimiento institucional Hospital Dr. Eduardo Castro Rendón. Provincia de Neuquén. Resumen., Documentos del PRESSAL, Buenos Aires, PRESSAL, septiembre, http:/ /www.msal.gov.ar/pressal

Fasano, V. y M. Alvarez (1997): Sistemas de información en salud. Marco conceptual, Buenos Aires Ministerio de Salud y Acción Social, Secretaría de Acción Social, Documentos del PRESSAL, http://www.msal.gov.ar/pressal

Ferlie, E., L. Ashburner y otros (1996): The New Public Management in Action, Oxford, Reino Unido, Oxford University Press.

Franch, L. (s.f.): Compromisos entre financiador público y proveedores de servicios, en APRESAL (Proyecto de apoyo a la reforma del sector salud), La reforma del sector salud, Ciudad de Guatemala.

Gallego, R. (1999): New public management. Reforms in the Catalan public health sector, 1985-1995, Londres, London School of Economics and Political Science, Government Department, tesis de doctorado.

Guzmán, A. (1999): Los compromisos de gestión en Costa Rica, 1997-2000, Madrid, Universidad Alcalá de Henares, julio, tesis de maestría.

IPSS-Tucumán (Instituto de Previsión y Seguridad Social de la Provincia de Tucumán) (1997): Estudio diagnóstico del IPSSTucumán, Documentos del PRESSAL, Buenos Aires, Proyecto de Desarrollo del Sector Salud en las Provincias Argentinas (PRESSAL), 16 de octubre, http://www.msaal.gov.ar/pressal 
Jaramillo, I. (2000): ¿Qué es y qué pasa con el régimen subsidiado de salud? Descripción y diagnóstico preliminar, Santafé de Bogotá, Ministerio de Salud de Colombia, Programa de Apoyo a la Reforma de Salud, enero.

Jaramillo, I., L. H. Sánchez y M. Ramírez (2000): Evaluación de la ley 100 de 1993. Seis años de su puesta en marcha, Santafé de Bogotá, Asociación Colombiana de la Salud, Grupo de Macropolíticas, abril.

Le Grand, J. (1999): Los nuevos desafíos de la política social: Estado, mercado y equidad. La experiencia del Reino Unido, en J. Carpio e 1. Novacovsky (comps.), De igual a igual: el desafío del Estado ante los nuevos problemas sociales, Buenos Aires, Fondo de Cultura Económica.

Le Grand, J. y W. Bartlett (eds.) (1993): The theory of quasimarkets, en J. Le Grand y W. Bartlett, Quasi-markets and Social Policy, Londres, MacMillan Press.

Lenz, R. (1998): Contribución incluida en: Chile, Ministerio de Salud, Políticas y estrategias innovadoras en salud. Reforma programática 1998, Santiago de Chile, Ministerio de Salud.

Londoño, B., I. Jaramillo y J.P. Uribe (1999): Descentralización y reforma en los servicios de salud: el caso colombiano, Santafé de Bogotá, Banco Mundial.

Mora, H. y M. P. Malabet (1998): Utilizaciones de servicios del Plan Obligatorio de Salud Subsidiado en una muestra de Administradoras del Régimen Subsidiado en Santafé de Bogotá, Coyuntura social, $\mathrm{N}^{\circ} 19$, Santafé de Bogotá, Fundación para la Educación Superior y el Desarrollo (FEDESARROLLO), noviembre.

Murray, C. y J. Frenk (2000): A WHO framework for health system performance assessment, Discussion papers, $\mathrm{N}^{\circ} 6$, Washington, D.C., WHO Statistical Information System (WHOSIS), http:/ /www-nt.who.int/whosis/statistics/menu.cfm?path=evidence

Neirotti, N. (1999): Control de gestión en políticas de salud. El caso de Mendoza, Argentina.

Ocampo, J. A. (1996): Participación privada en la provisión de los servicios sociales: el caso colombiano, Coyuntura social, $\mathrm{N}^{\circ}$ 14, Santafé de Bogotá, FEDESARrollo.

Ortiz, K. y S. Sequeira (1998): Análisis de los compromisos de gestión como instrumentos facilitadores del cambio organizacional en la Caja Costarricense del Seguro Social, San José, Universidad de Costa Rica, diciembre, tesis de maestría.

PRESSAL (1998): $1^{\text {er }}$ Seminario Regional. Contrato de gestión. Su implementación en las provincias, Cuadernos del PRESSAL, $\mathrm{N}^{\circ} 1$, Buenos Aires, PRESSAL. http://www.msal.gov.ar.pressal

Porter, D. (1999): Health, Civilisation and the State. A History of Public Health from Ancient to ModernTtimes, Routledge, Londres y Nueva York.

Ramírez, G., M. Araujo y otros (1998): Evaluación de tecnologías sanitarias y cuidado de salud basado en evidencias: herramientas para la reforma, en Chile, Ministerio de Salud, Políticas y estrategias innovadoras en salud. Reforma programática 1998, Santiago de Chile, agosto.

Rendón, P. e I. Jaramillo (1999): Evaluación del programa de mejoramiento de los servicios de salud en Colombia, Santafé de Bogotá, MINSALUD, mayo.

Salinas, H. (1988): Conferencia de Clausura, en Chile, Ministerio de Salud, Políticas y estrategias innovadoras en salud. Reforma programática 1998, Santiago de Chile, agosto.
Sánchez de León, A. (1998): Implementación de los contratos de gestión, Cuadernos del PRESSAL, $\mathrm{N}^{\circ} 1$, Buenos Aires, PRESSAL, http://www.msal.gov.ar/pressal

Sanhueza, G. y C. Jarpa (1998): Costo-efectividad en la toma de decisiones en salud, en Chile, Ministerio de Salud de Chile, Políticas y estrategias innovadoras en salud. Reforma programática 1998, Santiago de Chile, agosto.

Sojo, A. (1996): Posibilidades y límites de la reforma en la gestión de la salud en Chile, Revista de la CEPAL, N 59, LC/G.1931-P, CEPAL, Santiago de Chile.

(1997): La reforma finisecular del sector salud en América Latina y el Caribe: su derrotero e instrumentos, en Ministerio de Salud de Costa Rica/Fondo de las Naciones Unidas para la Infancia (UNICEF), Costa Rica. Las políticas de salud en el umbral de la reforma, serie Políticas sociales, $\mathrm{N}^{\circ} 1$, San José.

(1998): Los compromisos de gestión en salud de Costa Rica con una perspectiva comparativa, Revista de la CEPAL, $\mathrm{N}^{\circ} 66$, LC/G.2049-P, Santiago de Chile, CEPAL.

(1999a): Los compromisos de gestión en salud de Chile: formas de reintegración en el rompecabezas de la reforma, en Fondo Nacional de Salud, FONASA: ¿Una reforma en marcha? Una mirada interna y externa a las políticas y planes del Fondo Nacional de Salud, Santiago de Chile, julio.

(1999b): Los compromisos de gestión en salud de Costa Rica: algunas lecciones de un cuasimercado germinal, en CEPAL, Taller sobre evaluación de la gestión del gasto público en salud. Compendio de documentos 1999, Brasilia, enero.

(por publicarse a): ¿Qué son los compromisos de gestión?, en R. Lenz y H. Salinas (eds.), Salud pública y economía de la salud para no iniciados. Glosario para las reformas de salud en Latinoamérica, Santiago de Chile.

(por publicarse b): ¿Cómo lograr la equidad en las reformas de salud?, en R. Lenz y H. Salinas, Salud pública y economía de la salud para no iniciados. Glosario para las reformas de salud en Latinoamérica, Santiago de Chile.

Tafani, R. (1997): Reforma al sector salud en Argentina, serie Financiamiento del desarrollo, $\mathrm{N}^{\circ} 53$, Santiago de Chile, CEPAL.

The Economist (2000): A new prescription, Londres, The Economist Newspaper Ltd., 25 al 31 de marzo.

Universidad de Costa Rica (1998): Estudio de las principales normas de administración del recurso humano de la CCSS con base en el ordenamiento jurídico vigente, para determinar su congruencia y forma de adaptación al proceso de modernización institucional, San José de Costa Rica, Fundación de la Universidad de Costa Rica para la Investigación.

Vargas, J. E. y A. Sarmiento (1998): Descentralización de los servicios de educación y salud en Colombia, en E. Di Gropello y R. Cominetti (comps.), La descentralización de la educación y la salud. Un análisis comparativo de la experiencia latinoamericana, Santiago de Chile, CEPAL.

Walsh, K. (1995): Public Services and Market Mechanisms, Londres, Macmillan Press.

Winchester, David y Stephen Bach (1999): Britain. The transformation of public service employment relations, en S. Bach, L. Bordogna y otros, Public Service Employment Relations in Europe. Transformation, modernisation or inertia?, Routledge, London.re 